Etnográfica

Revista do Centro em Rede de Investigação em

Antropologia

vol. 21 (3) | 2017

Vol. 21 (3)

\title{
Ser índio e ser gay: tecendo uma tese sobre homossexualidade indígena no Brasil
}

Being native and being gay: weaving a thesis on indigenous homosexuality in Brazil

\section{Estevão Rafael Fernandes}

\section{(2) OpenEdition}

\section{Journals}

Edição electrónica

URL: https://journals.openedition.org/etnografica/5090

DOI: 10.4000/etnografica.5090

ISSN: 2182-2891

\section{Editora}

Centro em Rede de Investigação em Antropologia

\section{Edição impressa}

Data de publição: 1 outubro 2017

Paginação: 639-647

ISSN: 0873-6561

\section{Refêrencia eletrónica}

Estevão Rafael Fernandes, «Ser índio e ser gay: tecendo uma tese sobre homossexualidade indígena no Brasil», Etnográfica [Online], vol. 21 (3) | 2017, posto online no dia 24 março 2018, consultado o 09 fevereiro 2022. URL: http://journals.openedition.org/etnografica/5090 ; DOI: https://doi.org/10.4000/ etnografica.5090

\section{(c) (†) (5)}

Etnográfica is licensed under a Creative Commons Attribution-NonCommercial 4.0 International License. 


\section{Ser índio e ser gay: \\ tecendo uma tese sobre \\ homossexualidade indígena no Brasil}

\section{Estevão Rafael Fernandes}

Este artigo busca apresentar a subalternização da homossexualidade indígena no Brasil como parte inerente da colonização, fazendo uso das contribuições de autores two-spirit norte-americanos. Estrutura-se em uma apresentação de sua percepção enquanto "perda cultural"; a perspectiva two-spirit sobre a colonização enquanto processo heteronormativo; e algumas reflexões sobre o caso brasileiro. Demonstra-se que a colonização equivale, necessariamente, à criação de dispositivos para normalizar as sexualidades indígenas, moldando-as à ordem colonial. Assim, as práticas de disciplinamento e as respostas por parte dos indígenas nos permitem compreender mais sobre os movimentos indígenas, as relações interétnicas, políticas indigenistas, assim como relações de poder nestes contextos nacionais.

PALAVRAS-CHAVE: colonialismo, homossexualidade, etnologia, two-spirit, relações interétnicas.

Being native and being gay: weaving a thesis on indigenous homosexuality in Brazil - This paper aims to present the subordination of indigenous homosexuality in Brazil as an inherent part of the settlement, making use of the contributions of two-spirit authors. It brings the literature on the Brazilian indigenous peoples, demonstrating its recent perception as "cultural loss"; the two-spirit perspective on colonization as heteronormative process; and some thoughts on the Brazilian case. It is shown that colonization necessarily creates devices to normalize indigenous sexualities, shaping them to the colonial order. So, disciplining practices and responses by indigenous allow us to understand more about indigenous movements, interethnic relations, indigenous policies, as well as power relations in these national contexts.

KEYWORDS: Colonialism, homosexuality, ethnology, two-spirit, interethnic relations.

FERNANDES, Estevão Rafael (estevaofernandes@gmail.com) - Universidade Federal de Rondônia, Porto Velho (RO), Brasil. 
NO INÍCIO DE 2012 DEI INÍCIO À MINHA PESQUISA DE DOUTORADO sobre homossexualidade indígena no Brasil (Fernandes 2015). ${ }^{1}$ A pesquisa buscou ser uma reflexão mais aprofundada sobre homossexualidade em áreas indígenas - algo que, apesar de testemunhado por etnógrafos em campo usualmente, não era ainda alvo de uma preocupação mais sistemática na literatura antropológica brasileira.

Tenho consciência dos riscos e problemas inerentes ao uso da expressão "homossexualidade indígena" neste texto e pretendo abordá-los nas próximas páginas. ${ }^{2}$ Tais questões merecem uma nota explicativa para efeitos de introdução deste artigo, ainda que breve (para um olhar mais detido sobre esse ponto, cf. Fernandes e Arisi 2017).

A expressão "homossexualidade" (bem como "heteronormatividade") surge em um contexto temporal e social bastante específico - europeu, moderno e burguês - e trazê-lo aqui pode representar um duplo risco de viés eurocêntrico e anacrônico. Entretanto, em princípio a utilizo como expressão guarda-chuva para abranger as diversas práticas sexuais e afetivas fora do modelo heteronormado hegemônico, uma vez que cronistas e etnólogos que indicam a existência de tais práticas entre os povos indígenas no país o fazem utilizando expressões como "pecado nefando", “sodomia”, "pederastia” e "hermafroditismo", por exemplo. Ao utilizar "homossexualidade", aqui, indico não um sinônimo destes termos (cada qual situado sócio-historicamente em contextos discursivos específicos, como indicou Foucault 1988), mas, como espero deixar claro adiante, um marcador de diferença advindo do processo de colonização: ver e/ou ser visto como "homossexual" em um contexto interétnico possui implicações políticas, ontológicas e existenciais entrelaçadas com outros marcadores - étnicos, raciais, geracionais, etc. - cujo sentido pode ser plenamente compreendido dentro das relações coloniais, interétnicas, e das relações de poder que operam dentro desses coletivos.

Entendo, a partir dos dados obtidos e das várias falas ouvidas ao longo da pesquisa, que assumir-se como homossexual e indígena é, de alguma forma, contrapor-se ao modelo hegemônico (ocidental, cristão, moderno, "normal") de sexualidade. Nesse contexto, fica claro que, uma vez que expressões como "gay", "bicha", "veado" e "homossexual" alcançam as aldeias, também lá chega a carga de abjeção e preconceito que o modelo colonial impõe. Chamar este fenômeno de "homossexualidade indígena", desta forma, busca provocar não apenas uma reflexão sobre as implicações desta saída do armário em contextos indígenas, mas, também, sobre os próprios limites interpretativos de várias de

1 A pesquisa teve financiamento através do Edital Universal do CNPq (processo n. ${ }^{\circ}$ 4723 16/201 1-7) e do programa de doutorado sanduíche no exterior da Capes (processo n. ${ }^{\circ}$ 8145-13-0).

2 Agradeço a colaboração dos pareceristas anônimos da Etnográfica por haverem me chamado a atenção para este ponto. 
nossas chaves conceituais e categorias interpretativas - o que explica, em parte, minha opção por trabalhar com autores two-spirit, queer e críticos pós-coloniais, como Césaire, Fanon, Anzaldúa, Miñoso, Mbembe, dentre outros.

Tal discussão não é nova e surge desde, pelo menos, o texto de Luiz Mott (1997) intitulado "Etno-história da homossexualidade na América Latina", no qual o autor indaga "até que ponto o conceito de homossexualidade pode ser usado com propriedade heurística para descrever e interpretar as relações unissexuais do mundo extraeuropeu". Em que, pese o próprio autor não responder a esse questionamento ("deixarei ao leitor, ao final deste trabalho, tirar suas próprias conclusões”), os vários textos mencionados a seguir indicam que o avanço destas questões aponta para uma crítica tanto aos dispositivos que levaram à colonização das sexualidades indígenas (cf. Fernandes e Arisi 2017) quanto a várias noções bastante consolidadas de indianidade, identidade e gênero, e ainda à relação entre elas.

Desta maneira, ficará óbvia ao leitor minha opção, neste texto, de não partir "dos insights e debates na rica literatura etnográfica sobre corporalidade e socialidade entre os povos indígenas da América do Sul" (McCallum 2013: 57), mas tomar a homossexualidade indígena, nos termos acima, enquanto uma possibilidade epistêmica e como um locus de enunciação política. Este texto buscará desenvolver melhor essa ideia.

Neste sentido, apresentaremos, mesmo que de forma sucinta, um contraponto ao discurso - ouvido e lido por diversas vezes ao longo da pesquisa - de que a homossexualidade indígena se relaciona com uma eventual "perda da cultura", um "contágio advindo do contato", surgido sobretudo desde meados da década de 1970 (em especial na imprensa). Ao longo da pesquisa, ficou claro que várias das lideranças indígenas manifestavam essa mesma opinião. ${ }^{3}$ Alguns exemplos ilustrativos disso são facilmente localizados em uma pesquisa pelo tema na mídia brasileira.

Em 27 de julho de 2008, a Folha de São Paulo publica uma reportagem intitulada "Índios gays são alvo de preconceito no AM":

"Entre os índios ticuna, a etnia mais populosa da Amazônia brasileira, um grupo de jovens não quer mais pintar o pescoço com jenipapo para ter a voz grossa, como a tradição manda fazer na adolescência, nem aceita as regras do casamento tradicional, em que os casais são definidos na infância.

Esse pequeno grupo assumiu a homossexualidade e diz sofrer preconceito dentro da aldeia, onde os gays são agredidos e chamados de nomes pejorativos como 'meia coisa'. Quando andam sozinhos, podem ser alvos de pedras, latas e chacotas. $[\ldots]$ 
O cientista social e professor bilingue (português e ticuna) de história Raimundo Leopardo Ferreira afirma que, entre os ticunas, não havia registros anteriores da existência de homossexuais, como se vê hoje. Ele teme que, devido ao preconceito, aumentem os problemas sociais entre os jovens, como o uso de álcool e cocaína.

'Isso [a homossexualidade] é uma coisa que meus avós falavam que não existia', afirmou”. ${ }^{4}$

Quase um ano depois, em 23 de maio de 2009, a Gazeta Online publica uma reportagem com o título "ONGs denunciam exploração sexual de jovens indígenas gays e travestis em Roraima". ${ }^{5} \mathrm{O}$ relato narra a vida de indígenas da Terra Indígena Raposa/Serra do Sol que, muitas vezes fugindo da violência proveniente de familiares em suas casas, acabam se prostituindo em cidades como Boa Vista - como o caso da travesti Paulina, da etnia makuxi, garota de programa na capital roraimense. Alguns meses antes, em 02 de março daquele ano, a imprensa mato-grossense divulgava no portal de notícias 24 Horas News a matéria "Revelado drama de índios gays do Mato Grosso". ${ }^{6}$

Como no caso dos tikuna e dos makuxi acima, os umutima que assumem sua homossexualidade sofrem agressões físicas e verbais, tendo que se afastar de suas famílias para morar na cidade de Barra do Bugres, onde acabam se travestindo e tornam-se garotas de programa. Como esses, há vários outros relatos, se não em reportagens que surgem, aqui ou lá, nas rodas de conversas de etnólogos, pesquisadores e trabalhadores em saúde junto a povos indígenas. As narrativas mencionadas acima, se lidas atentamente, deixam claro como essa perspectiva é permeada não apenas dos preconceitos subjacentes ao contato interétnico quanto, especialmente, das relações de poder que operam no cotidiano daqueles sujeitos.

Desta forma, buscar-se-á indicar a literatura desde a qual partiu meu referencial analítico: as críticas two-spirit, com vistas a apontar como a colonização significou (e significa) para os povos indígenas um encadeamento de dispositivos de heterossexualização compulsória: políticas de casamento interétnico, de escolarização, de trabalho nas aldeias e mesmo atos como vestir, dar nomes ou cortar os cabelos dos indígenas implicaram/implicam, necessariamente, em incorporá-los a um modelo de sexualidade hegemônico.

4 O texto é assinado por Kátia Brasil, da Agência Folha, e está disponível em < http://wwwl.folha.u ol.com.br/fsp/brasil/fc2707200821.htm > (última consulta em outubro de 2017).

5 Assinada pela Agência Estado e disponível em < http://gazetaonline.globo.com/_conteudo/2009/05 191533-ongs + denunciam + exploracao + sexual + de + jovens + indigenas + gays $+\mathrm{e}+$ travestis $+\mathrm{em}+$ rorai ma.html > (última consulta em outubro de 2017).

6 Assinada pela Redação do Toda Forma de Amor, com informações do 24 Horas News e reportagem de Raoni Ricci. 
Ainda que abundem dados neste sentido nos documentos e literatura sobre as políticas indigenistas no país, sua sistematização mais ampla aos moldes de trabalhos como Stoler $(1995,2002)$ e Young (2005) é ainda algo a ser feito na antropologia brasileira. Entretanto, em que pesem as potencialidades analíticas desses autores no tocante à relação entre raça, sexo e colonização, lhes falta um olhar mais aproximado aos contextos indígena e homossexual - tal olhar me foi apontado pelos autores two-spirit norte-americanos, possibilitando, desde a perspectiva comparada com o contexto brasileiro, realizar um "arco interpretativo" (Oliveira 2000). Assim, nosso esforço será o de apresentar, neste texto, o pensamento two-spirit como meio de acessar a homossexualidade indígena pensada enquanto crítica ao processo colonial. Ao final, apresentaremos algumas conclusões sobre o contexto brasileiro, a partir da experiência indígena norte-americana.

\section{ESTABELECENDO UM ARCO INTERPRETATIVO: OS TWO-SPIRIT}

A fim de tentar compreender essas narrativas, busquei estabelecer o que Cardoso de Oliveira (2000) chama de "arco interpretativo": um exercício de elucidação recíproca, a partir de uma perspectiva comparada. Nesse caso, o contraponto foi encontrado na formação do movimento two-spirit, como chave de interpretação para a compreensão dessas sexualidades não hegemônicas em povos indígenas.

Em 1990, por ocasião da Third Native American/First Nations Gay and Lesbian Conference, em Winnipeg, estudiosos, indígenas e ativistas resolveram adotar o termo "two-spirit". A escolha da expressão two-spirit, proveniente da expressão ojibwa niizh manitoag, possui implicações de natureza política. Como escrevem Jacobs, Thomas e Lang:

"Muitos homens nativo-americanos urbanos tentaram voltar para casa em suas reservas para passar seus últimos anos com suas famílias antes de morrer por complicações da infecção pelo HIV. Cada um de nós ouviu histórias pessoais de homens que não eram bem-vindos em 'casa' porque eles tinham 'doença de gay branco' e que homossexualidade não era parte da cultura tradicional. Usando a palavra 'two-spirit', enfatiza-se o aspecto espiritual da vida e minimiza-se a persona homossexual" (1997: 3, tradução minha).

Roscoe (1998: 100 ss.) traça um panorama dos caminhos que levaram a essa articulação - advinda tanto das lutas pelos direitos homossexuais em San Francisco (Califórnia) quanto das lutas indígenas na América do Norte, e ainda, posteriormente, pelas demandas surgidas com o aparecimento da AIDS. O marco dessa luta foi, justamente, a fundação da GAI (Gay American Indian), em 1975. A articulação que levou à criação dessa organização apenas 
foi possível após a ocupação de Alcatraz por ativistas indígenas, em novembro de 1969: o movimento Red Power deu aos grupos indígenas - inclusive àqueles marginalizados, como os homossexuais - coragem para organizarem-se e enfrentarem o aparato pós-colonial. Até então, os indígenas homossexuais eram vistos como párias, mesmo pelos indígenas, e como resultado da ação colonial (que incluía práticas como conversão forçada, integracionismo sexual, corte de seus cabelos como forma de humilhação e, eventualmente, assassinatos). O discurso que então as lideranças indígenas proferiam era, majoritariamente, no sentido de que a homossexualidade refletia todas as atitudes avançadas pelo discurso heteronormativo ocidental de que a homossexualidade corresponderia à depravação.

Contudo, como resultado indireto desse percurso, Roscoe sinaliza que crescia a consciência de tradições de gêneros alternativos, não apenas pela memória oral, mas através de livros que buscavam retratar essas realidades - como Living the Spirit (Roscoe 1988) e The Spirit and the Flesh (Williams 1992). Assim, as organizações homossexuais indígenas começaram a ter como bandeira de luta recuperar o papel "tradicionalmente sagrado" dos two-spirit em suas culturas.

Nas palavras de Sue Beaver (mohawk):

"Nós acreditamos que existe o espírito tanto de homem quanto de mulher interiormente. Olhamos para nós mesmos como sendo muito privilegiados. $\mathrm{O}$ Criador criou seres muito especiais, quando criou os two-spirit. Ele deu a alguns indivíduos dois espíritos. Nós somos pessoas especiais, e isso tem sido negado desde o contato com os europeus... O que os heterossexuais alcançam no casamento, nós conseguimos dentro de nós mesmos" (Roscoe 1998: 109, tradução minha).

$\mathrm{Na}$ verdade, mais do que a adoção de termos como gay, gênero alternativo, berdache, etc., o termo two-spirit recuperava um papel tradicional e sagrado - diferentemente dos demais termos, como berdache. Além disso, ao fazê-lo, tornava-se uma postura anticolonial, por não mais aceitar as categorias ocidentais de classificação de determinadas práticas.

As ponderações do ativista cherokee Qwo-Li Driskill vão nesse sentido:

“... as críticas two-spirit apontam para a incumbência de os estudos queer examinarem o colonialismo em curso, o genocídio, a sobrevivência e a resistência das nações e povos indígenas. Além disso, eles desafiam os estudos queer para confundir as noções de nação e de diáspora, prestando atenção às circunstâncias específicas das nações indígenas nos fundamentos territoriais dentro dos quais Estados Unidos e Canadá colonizam. Para levar as perguntas acima mais adiante, eu gostaria de perguntar o que as críticas two-spirit podem nos dizer sobre essas mesmas questões. Além disso, o que 
essas críticas podem nos dizer sobre nação, diáspora, colonização e descolonização?" (Driskill 2010: 86, tradução minha).

O que parece claro, aqui, é que a atualização dessa identidade não pode ser compreendida fora do contexto pós-colonial. Assim, para compreendermos a emergência, ou não, de movimentos indígenas homossexuais, faz-se necessário buscar entendê-los não apenas enquanto demandas de gênero ou sobre o corpo, mas, sobretudo, como fenômenos políticos relacionados à forma como sua relação com o Estado, com os próprios indígenas e com a sociedade envolvente se mantém. A literatura acumulada a partir do contexto etnográfico norte-americano pode nos apontar desafios e direções às quais, dada a (ainda) parca produção acadêmica sobre o tema produzida sobre povos indígenas no Brasil, não temos votado a devida atenção.

\section{(R)EXISTINDO COMO INDÍGENA E GAY}

Em comum nas situações brasileira e norte-americana, talvez, suas sexualidades dissonantes em relação ao modelo hegemônico estabelecido por uma lógica ocidental, moderna, cristã e branca. Mas podemos ir além: a comparação entre as sexualidades indígenas no Brasil e as críticas e pensamentos two-spirit nos indica algumas direções.

Em primeiro lugar, não se pode afirmar que os percursos da colonização dos povos indígenas no Brasil e nos Estados Unidos tenham seguido caminhos inteiramente divergentes. Em ambos houve momentos marcados por missões, integração forçada, deslocamentos forçados, escolas que buscassem "civilizá-los" compulsoriamente. Da mesma forma, o manejo moral dos povos indígenas, seja por meio de castigos ou de imposição de nomes próprios, padrões de divisão de trabalho ou educação baseados no binarismo sexual, era parte fundamental de sua incorporação compulsória ao sistema colonial. Entendo que, mesmo em diferentes contextos nacionais, ambos estivessem sujeitos às mesmas ordens discursivas, sendo compulsoriamente colonizados em suas sexualidades a partir de projetos nacionais, civilizatórios, religiosos, integracionistas e enquadramentos diversos que buscassem manter a diferença colonial.

Desta forma, a colonização das sexualidades indígenas, pensada a partir das críticas two-spirit, nos mostra como tais processos não podem ser compreendidos separadamente das relações de trabalho e dos modelos de moral e família hegemônicos. Tais processos incidem sobre, e desarticulam, as redes de casamento, parentesco, moradia, alianças e vida doméstica dos povos indígenas, na medida em que buscam normalizar espaços, temporalidades e subjetividades indígenas. À colonização corresponde, necessariamente, a criação de um aparato burocrático-administrativo, político e psicológico para normalizar as sexualidades indígenas, moldando-as à ordem colonial. $\mathrm{O}$ poder colonial se 
assenta nessa assimetria de forças - ontológicas, epistemológicas, políticas - de tal modo a abrir uma fissura naquelas pessoas cujas vidas não se enquadrem nos modelos hegemônicos.

Desta forma, a retórica da homossexualidade enquanto "contágio" passa a adquirir um novo sentido, não mais o da perda da "identidade indígena" - pautada, neste discurso, a partir de um índio hiper-real (Ramos 1995), a-histórico -, mas enquanto "poluição" para o projeto/processo civilizador: o índio gay subverte duplamente o ideal colonizador; moralmente, por sua sexualidade, e etnicamente, por sua indianidade. Acusar o indígena homossexual de "estar perdendo sua cultura", desta forma, é focar sobre uma dessas subversões, trazendo o debate para dentro da esfera dos "civilizados": esvaziando-se a diferença étnica, esvazia-se também a necessidade de se pensar as fissuras abertas pelo processo colonial.

Em outros termos, a dupla exclusão (étnica e sexual) mostra as feridas causadas pela colonização em curso, obrigando a cultura do colonizador a reconhecer suas próprias contradições. Dessa maneira, retomando especificamente a homossexualidade indígena, poderíamos dizer que a civilização, baseada em ideais da cultura moderna/colonial branca, cristã, patriarcal e heterossexual, impôs aos povos indígenas um aprisionamento a uma imagem, a vitimização eterna em uma essência (cf. Fanon 2008: 30, 47): um indío hiper-real, a-histórico, sem conflitos internos, sexualidades, desejos ou afetos. A homossexualidade indígena não é, desta perspectiva, sinal de "perda cultural", mas, antes, sua invisibilidade e subalternização são resultado de dinâmicas coloniais ainda em curso.

\section{BIBLIOGRAFIA}

DRISKILL, Qwo-Li, 2010, “Doubleweaving: two-spirit critiques - building alliances between native and queer studies”, GLQ: A Journal of Lesbian and Gay Studies. 16 (1-2): 69-92.

FANON, Frantz, 2008, Pele Negra, Máscaras Brancas. Salvador, Edufba.

FERNANDES, Estevão R., 2015, Decolonizando Sexualidades: Enquadramentos Coloniais e Homossexualidade Indígena no Brasil e nos Estados Unidos. Brasília, CEPPAC, Universidade de Brasília, tese de doutorado em Estudos Comparados sobre as Américas.

FERNANDES, Estevão R., e Bárbara M. ARISI, 2017, Gay Indians in Brazil: Untold Stories of the Colonization of Indigenous Sexualities. Cham, Springer.

FOUCAUlT, Michel, 1988, História da Sexualidade I: A Vontade de Saber. Rio de Janeiro, Graal. JACOBS, Sue Ellen, Wesley THOMAS, e Sabine LANG (orgs.), 1997, Two-Spirit People: Native American Gender Identity, Sexuality, and Spirituality. Urbana, University of Illinois Press. 
McCALlUM, Cecilia, 2013, “Nota sobre as categorias 'gênero' e 'sexualidade' e os povos indígenas", Cadernos Pagu, 41: 53-61.

MOTT, Luiz, 1997, "Etno-história de la homosexualidad en América Latina”, Historia y Sociedad, 4: 123-144.

OLIVEIRA, Roberto Cardoso de, 2000, "A dupla interpretação da antropologia”, em R.C. de Oliveira, O Trabalho do Antropólogo: Olhar, Ouvir, Escrever. São Paulo, Editora da Unesp/Brasília, Paralelo 15, 95-106 (2. ${ }^{a}$ edição).

RAMOS, Alcida R., 1995, "O índio hiper-real", Revista Brasileira de Ciências Sociais, 28 (10): 5-14.

ROSCOE, Will, 1988, Living the Spirit: A Gay American Indian Anthology. Nova Iorque, St. Martin's Press.

ROSCOE, Will, 1998, Changing Ones: Third and Fourth Genders in Native North America. Nova Iorque, St. Martin's Press.

STOLER, Ann Laura, 1995, Race and the Education of Desire: Foucault's History of Sexuality and the Colonial Order of Things. Durham, Duke University Press.

STOLER, Ann Laura, 2002, Carnal Knowledge and Imperial Power: Race and the Intimate in Colonial Rule. Berkeley, University of California Press.

WILliams, Walter L., 1992, The Spirit and the Flesh: Sexual Diversity in American Indian Culture. Boston, MA, Beacon Press (2. ${ }^{a}$ edição revista).

YOUNG, Robert J. C., 2005, Desejo Colonial. São Paulo, Perspectiva. 